\title{
Psychometric Analysis of the Flow Short Scale translated to Finnish
}

\author{
Michael Laakasuo ${ }^{a}$, Jussi Palomäki ${ }^{a}$, Sami Abuhamdeh ${ }^{b}$, Otto Lappi ${ }^{a, c}$ and Benjamin \\ Ultan Cowley ${ }^{a, d, x}$ \\ ${ }^{a}$ Cognitive Science, Department of Digital Humanities, Faculty of Arts, University of Helsinki; Siltavuorenpenger 1 A, 00012 Helsinki, Finland \\ ${ }^{b}$ Department of Psychology, Marmara University, Istanbul, Turkey \\ ${ }^{c}$ Traffic Research Unit, University of Helsinki, Helsinki, Finland \\ ${ }^{d}$ Faculty of Educational Sciences, University of Helsinki, Helsinki, Finland \\ ${ }^{x}$ Corresponding author
}

\section{ARTICLE INFO}

\section{Keywords:}

Flow

Finnish Flow Short Scale

Scale validation

Psychometrics

\begin{abstract}
A B S T R ACT
We report a psychometric scale validation study on a Finnish translation of the Flow Short Scale (FSS). Data from 201 Finnish speaking participants were collected via the Prolific Academic platform. To analyse the scale's factorial structure, we performed Mokken scale analysis, Parallel Analysis, Very Simple Structures analysis and a standard Confirmatory Factor Analysis. Then, we evaluated the correlations between FSS and two other Flow scales, the Flow State Scale and Flow Core Scale. Finally, we evaluated the FSS's ability to distinguish Flow-inducing experiences from boring (non-Flow-inducing) experiences. Collectively the results showed that an 8-item, two-factor version of the scale was a justified instrument with good psychometric properties.
\end{abstract}

\section{Introduction}

Flow is an intrinsically rewarding psychological state characterized by deep attentional involvement in the task at hand [Nakamura and Csikszentmihalyi, 2002]. Ever since Csikszentmihalyi's introduction of Flow in 1975, there has been increasing interest in the concept. Today, the Flow experience is the focus of hundreds of empirical studies from a diversity of fields including educational psychology, recreation and leisure sciences, game design, and many others.

The researcher who wishes to investigate Flow, however, faces numerous methodological uncertainties. One of these is the important question of how to operationalize Flow, which has not been done in a consistent way. Indeed, a recent review of Flow operationalizations found that, across the 42 reviewed studies (from 2014-'19), Flow was operationalized in 24 distinct ways [Abuhamdeh, 2020]. A second issue faced by many researchers who wish to investigate Flow is the limited number of scales that have been validated for use in languages other than English. Such revalidation studies are crucial, because one cannot assume that a scale developed in one language will perform similarly when adapted to another language. Thus, pending an international consensus study to develop a universal multilingual Flow instrument, the most parsimonious way to operationalize Flow for a given language context is to translate and revalidate an existing, popular Flow scale.

The purpose of the current study is twofold: first, to translate and revalidate an existing Flow scale for the Finnish language; second, by re-examining the factor structure of the scale, we aim to contribute insight into the generalizeability of the original scale across languages and contexts. Existence of a validated short Flow scale would be valuable in the Finnish context, since there is a wealth of human-focused research in relevant areas, such as education, music, games and gambling, sports, and traffic psychology.

Examining the state of the art, Abuhamdeh's review [Abuhamdeh, 2020] illustrates that there are few widelyused instruments for assessing state Flow (as opposed to trait Flow, or propensity to experience Flow), with the Flow State scale [Jackson and Marsh, 1996] being the most popular general-purpose scale, and Flow Short [Engeser and Rheinberg, 2008] and Core scales used less frequently. Revalidations of some of these scales have been published to adapt them to specialist domains, such as reading [Thissen, Menninghaus, and Schlotz, 2018], web browsing [Mahnke, Wagner, and Benlian, 2012], and clinical populations [Huang, Hu, Wu, Yang, Lee, Fang, Huang, Lai, and Yu, 2019].

We conducted another literature review to assess whether these scales have been revalidated for other languages. We searched for each scale's exact name on Scopus under Title, Abstract, and Keywords - we obtained 82, 20, and zero hits

$\operatorname{ORCID}(\mathrm{s})$ : 
for State, Short, and Core scales respectively. Examining the results of this search suggests that there have been no validation studies of Short or Core scales in new languages. We found domain-specific revalidated translations of the Flow State scale for athletics (Turkish [Çağlar, Sari, Aş̧̧i, Eklund, and Jackson, 2020]; Brasilian Portuguese [Hernandez and Voser, 2019]; Spanish [García Calvo, Jiménez Castuera, Santos-Rosa Ruano, Reina Vaíllo, and Cervelló Gimeno, 2008]; French [Fournier, Gaudreau, Demontrond-Behr, Visioli, Forest, and Jackson, 2007]; Greek [Doganis, Iosifidou, and Vlachopoulos, 2000]), music performance (Spanish [Moral-Bofill, Andrés Lópezdelallave, Pérez-Llantada, and Holgado-Tello, 2020] - notably, this study found issues with the item related to temporal effects in Flow, as did we), occupational therapy (Japanese [Yoshida, Asakawa, Yamauchi, Sakuraba, Sawamura, Murakami, and Sakai, 2013]). The Flow State scale has also been revalidated in a Japanese translation for general-purpose use [Kawabata, Mallett, and Jackson, 2008], while the Dispositional Flow trait scale has been translated and validated for general use in Italian [Riva, Riva, Talò, Boffi, Rainisio, Pola, Diana, Villani, Argenton, and Inghilleri, 2017].

With respect to the Flow Short Scale [Engeser and Rheinberg, 2008], we found only one revalidation, which examined the factor structure of a Greek version of the scale [Kyriazos, Stalikas, Prassa, Galanakis, Flora, and Chatzilia, 2018]. In that study, the final scale structure was notably different from the one found in the original validation study [Rheinberg, Vollmeyer, and Engeser, 2003]. This result serves to underscore the importance of examining the performance of the Flow Short Scale in both different languages and different contexts.

The Flow Short Scale (hereafter FSS) [Engeser and Rheinberg, 2008], designed to measure state-level Flow, was chosen here for translation and revalidation in Finnish based on two primary considerations. First, because Flow is often measured in the context of repeated measures designs, we sought a short scale, one that would minimize participant burden. Conveniently, the FSS consists of only ten items. Second, because we worked under the assumption that others may subsequently use our derived scale, we sought a scale which was relatively popular among Flow researchers. FSS has indeed been used to assess Flow in the context of a wide range of sports, games, and other goal-directed activities (e.g. Brom, Děchtěrenko, Frollová, Stárková, Bromová, and D’Mello [2017], Schattke, Brandstätter, Taylor, and Kehr [2014], Harris, Vine, and Wilson [2017], Hermann and Vollmeyer [2016]. As indicated above [Abuhamdeh, 2020], the Flow State Scale [Jackson and Marsh, 1996] is the more popular of the two most commonly used scales to measure state-level Flow. However, we preferred the FSS because 1) the FSS conflates the experience of Flow and the conditions of Flow to a lesser degree than the Flow State Scale, and 2) the FSS is shorter than the Flow State Scale.

In summary, our experiments and analyses, detailed below, together suggest that an 8-item, two-factor Finnish FSS - that excludes items 1 and 3 from the original scale - is a justified, validated psychometric instrument.

\section{Method}

Finnish FSS was first used as the dependent variable (DV) in previous studies on the relationship between Flow and performance, conducted the authors [Cowley, Palomäki, Tammi, Frantsi, Inkilä, Lehtonen, Pölönen, Vepsäläinen, and Lappi, 2019, Palomäki, Tammi, Lehtonen, Seittenranta, Laakasuo, Abuhamdeh, Lappi, and Cowley, 2021]. We subsequently determined the need (outlined above) to fully validate the translated scale with a separate study designed for scale validation (that is, larger sample size and no performance task). We obtained such data via the Prolific Academic online platform. We performed a series of psychometric analyses focused on the FSS and its factorial structure (Mokken scale analysis, Parallel Analysis, Very Simple Structures analysis and Confirmatory Factor Analysis). Then, we performed a sensitivity analysis evaluating the correlations between FSS and two other well-known Flow state scales, the Flow State Scale [Jackson and Marsh, 1996] and Flow Core Scale [Martin and Jackson, 2008]. Finally, we evaluated the FSS's ability to discriminate between "Flow-inducing" and "boring" experiences.

\subsection{Participants}

In total, 201 Finnish speaking individuals (94 female, mean age $=29.2$ ) participated in a cross-sectional study on the commercial online platform Prolific Academic. Of the participants, 89 (44.5\%) had at least a bachelor's degree. Participants were compensated 1.5 pounds sterling (about 1.76 euros), and participation took 15.2 minutes on average.

The current study was run as a part of a larger project [Palomäki et al., 2021], which was approved by the University of Helsinki Ethical review board in humanities and social and behavioral sciences (statement 31/2017; study title MulSimCoLab). Under Finnish law, this particular experiment did not require ethical permission as it was non-invasive, non-sensitive research conducted on adults. The experiment was carried out in accordance with the code of ethics of the world medical association (Declaration of Helsinki) for experiments involving humans. Informed consent was obtained from all participants. 


\subsection{Procedure}

The design was cross-sectional. Participants first gave informed consent and then completed all psychometric measures in the same order. Before the measures, participants read instructions telling them to spend one minute to recall and visualize a previously experienced Flow-inducing event [as per Jackson and Marsh, 1996], and were then asked to write down a short description (max 10 words) of that event in a text box.

On the next pages the participants were instructed to fill in the Flow Short Scale, Flow Core Scale, and Flow State Scale in that order, based on their memory of the Flow-inducing event. After filling in the scales, participants were instructed to recall and visualize a boring, non-Flow-inducing, event and again fill in the Flow Short Scale, but this time based on their memory of the boring event (translations below). As before, participants were also asked to give a short 10-word description of their (boring) experience. Finally, all participants were debriefed, thanked and dismissed.

Before filling in the FSS for the first time, participants received the following instructions to recall a 'Flow-like experience' (translated from Finnish):

"After about 1.5 minutes, a button will show up at the bottom of the screen - click on it to continue. On the next page you will be asked questions regarding a small exercise we would like you to do. Use this short waiting time to recall a successful experience that required some skill but happened fluently, and in which you absorbed in (an experience where you felt like in a 'Flow' state). It can be a positive experience of rock climbing, playing the guitar, meditating, or a successful motocross track - it can be anything. It doesn't matter what the experience or situation was, as long as it was a 'Flow' experience to you, yet also challenging. However, it is important that you concentrate on imagining this experience vividly."

Before filling in the FSS for the second time, participants received the following instructions to recall a "boring experience" (translated from Finnish):

"Now we would like you to repeat the previous exercise, but this time we ask you to recall a situation that has been particularly dull, perhaps difficult and boring, and felt like lasting forever (a situation where you definitely did not experience a 'Flow' state). It can be, for example, a particularly unexciting day at a summer job at an assembly line or drag and tiresome cleaning day, or a mechanical and repetitive task, but one that is challenging enough to keep you from focusing even on your own thoughts. It doesn't matter what the experience or situation was, as long as it was particularly dull and boring. However, it is important that you concentrate on imagining this experience vividly."

\subsection{Materials}

\subsubsection{Flow Short Scale (FSS)}

The FSS [Engeser and Rheinberg, 2008] is a 10-item scale composed of two sub-scales - one intended to measure "absorption" (4 items; e.g. "I do not notice time passing"), and the other intended to measure performance "fluency" (6 items; e.g. "My thoughts/activities run fluidly and smoothly"). The scale is evaluated on a 7-point Likert scale with anchors varying from "Not at all" to "Very much". An additional 3 item measure of perceived importance is administered with the FSS to determine the experienced importance of the given task (e.g. "I must not make any mistakes here").

The FSS items were first translated from English to Finnish, but modified slightly to reflect the game-like experimental task used in [Cowley et al., 2019, Palomäki et al., 2021]. Table 1 shows the items in their original form (right column), the Finnish version (left column) translated from the original, and the English version translated from the Finnish (middle column). In this validation study the activity to be reflected on could be anything (unlike in [Cowley et al., 2019], where participants reflected on the game-like task), so the items referring to "playing" were changed minimally to refer to "activity" (e.g., item 10 ["Syvennyin peliin täysin" / "I delved into the game fully"] was changed into ["Syvennyin toimintaan täysin" / "I delved into the activity fully"]). Note that in the original item 2, the words "fluidly" and "smoothly" are almost synonymous, and in a gaming context, they are aptly captured by the single word "sujuvasti" (which could also mean "fluently"). 
Table 1

Translated and back-translated FSS items (modified for the current study)

\begin{tabular}{|c|c|c|c|}
\hline Item & Finnish Translation & Back-translation & Original English \\
\hline 1 & $\begin{array}{l}\text { Peli tuntui juuri sopivan } \\
\text { haastavalta }\end{array}$ & $\begin{array}{l}\text { Playing the game, I felt just } \\
\text { the right amount of challenge }\end{array}$ & I feel just the right amount of challenge \\
\hline 2 & Pelasin sujuvasti & I played fluently & $\begin{array}{l}\text { My thoughts/activities run fluidly } \\
\text { and smoothly }\end{array}$ \\
\hline 3 & En huomannut ajankulkua & I did not notice time passing & I do not notice time passing \\
\hline 4 & Pystyin hyvin keskittymään & I found it easy to concentrate & I have no difficulty concentrating \\
\hline 5 & Mieleni oli selkeä & My mind was clear & My mind is completely clear \\
\hline 6 & Uppouduin täysin pelaamiseen & $\begin{array}{l}\text { I immersed (myself) fully in } \\
\text { playing }\end{array}$ & I am totally absorbed in what I am doing \\
\hline 7 & $\begin{array}{l}\text { Löysin oikeat liikkeet kuin } \\
\text { itsestään }\end{array}$ & $\begin{array}{l}\text { I found the right moves } \\
\text { spontaneously }\end{array}$ & $\begin{array}{l}\text { The right thoughts/movements occur } \\
\text { of their own accord }\end{array}$ \\
\hline 8 & Olin koko ajan tilanteen tasalla & $\begin{array}{l}\text { I was able to cope with the task } \\
\text { all the time }\end{array}$ & $\begin{array}{l}\text { I know what I have to do each step } \\
\text { of the way }\end{array}$ \\
\hline 9 & Tunsin hallitsevani tilannetta & $\begin{array}{l}\text { I felt in control of the situation / } \\
\text { I felt I had everything in control }\end{array}$ & I feel that I have everything under control \\
\hline 10 & Syvennyin peliin täysin & I delved into the game fully & I am completely lost in thought \\
\hline 11 & $\begin{array}{l}\text { Koin pelissä onnistumisen } \\
\text { tärkeäksi }\end{array}$ & $\begin{array}{l}\text { It was important to me to } \\
\text { succeed in the game }\end{array}$ & $\begin{array}{l}\text { Something important to me is at } \\
\text { stake here }\end{array}$ \\
\hline 12 & $\begin{array}{l}\text { Minusta tuntui siltä, etten saisi } \\
\text { tehdä yhtäkään virhettä }\end{array}$ & $\begin{array}{l}\text { I felt like I shouldn't make } \\
\text { any mistakes }\end{array}$ & I must not make any mistakes here \\
\hline 13 & Pelkäsin epäonnistuvani & I was worried about failing & I am worried about failing \\
\hline
\end{tabular}

\subsubsection{Flow Core Scale}

The Flow Core Scale [Martin and Jackson, 2008] is a 10-item uniform scale intended to measure the state of "being in Flow" or "the zone". Items are evaluated on a 7-point Likert scale from 1 ("Strongly disagree") to 7 ("Strongly agree"). Example items are "I am "in the zone"” and "I am "totally involved"".

\subsubsection{Flow State Scale}

The Flow State Scale [Jackson and Marsh, 1996] is a 36-item scale comprising 9 subscales with 4 items each. The subscales (example item in brackets) are: Challenge-skill balance ("I was challenged, but I believed my skills would allow me to meet the challenge"), Action-awareness merging ("I made the correct movements without thinking about trying to do so"), Clear goals ("I knew clearly what I wanted to do"), Unambiguous feedback ("It was really clear to me that I was doing well"), Concentration on task at hand ("My attention was focused entirely on what I was doing"), Paradox of control ("I felt in total control of what I was doing"), Loss of self-consciousness ("I was not concerned with what others may have been thinking of me"), Transformation of time ("Time seemed to alter (either slowed down or speeded up)"), and Autotelic experience ("I really enjoyed the experience"). Items are evaluated on a 7-point Likert scale from 1 ("Strongly disagree") to 7 ("Strongly agree").

\subsection{Analyses}

We first ran a Mokken scale analysis on the FSS. Mokken scale analysis refers to a series of procedures where individual scale items and their properties are investigated in the context of the whole scale [we followed the guidelines of Sijtsma and van der Ark, 2017]. The analysis includes a number of distinct steps depending on the intended purpose and technical details of the scale. We present the results for a 1) homogeneity analysis for individual items (i.e. normed corrected item-scale covariance), 2) scalability analysis using the automated item selection procedure (AISP; to evaluate scale structure across multiple homogeneity index values), and 3) monotonicity analysis for individual items (i.e., 
do higher scores on individual items correspond to higher scores on the whole scale). We also performed Paralleland Very Simple Structure -analyses [Revelle and Rocklin, 1979, Dima, 2018, van der Linden, 2016] to evaluate the factorial structure of the scale. Finally, based on the results of these analyses, we performed a standard Confirmatory Factor Analysis (CFA) using the Satorra-Bentler estimation method on a two-factor solution of the FSS. Since the two factors are allowed to correlate freely, this analysis is analogous to an oblique rotation method in an exploratory factor analysis.

The R syntax for all analyses reported here (alongside the data) can be found at https://doi.org/10.6084/ m9.figshare.14394446.

\section{Results}

The item-level homogeneity analysis is presented in Table 2 . The recommended cut-off point for item homogeneity index values (also known as scalability coefficients) in the literature is .30 [Sijtsma and van der Ark, 2017], which is not reached by items 1 and 3 .

The scalability analysis on different homogeneity index cut-off values is presented in Table 3 . This analysis reveals how the average homogeneity of the whole scale changes when items load on different factors. In Table 2, zeros indicate unscalable items, ones across indicate a one-factor solution, and a combination of both ones and twos indicate a two-factor solution for the whole scale. The analysis implies that, excluding items 1 and 3, a moderately scalable instrument can be formed from items 2 , and 4-10. Higher scalability values seem to result in a theoretically unsound scale structure. According to Sijtsma and van der Ark [2017], scalability index values should be at least .30, but preferably as high as possible. The FSS has acceptable scalability (between .35 and .45) when items 1 and 3 are dropped.

We then performed a monotonicity analysis. According to the monotonicity violation indices, two clear violators of monotonicity, at the scalability index value of .35, were items 1 and 3. Items 4 and 8 violated monotonicity minimally, while items 6 and 10 had a single minor monotonicity violation each [Dima, 2018]. Note that items 1, 3, 6 and 10 form the Absorption subscale in FSS according to the original scale structure [Engeser and Rheinberg, 2008]. For graphical presentation of the monotonicity functions of individual items, see Figure 1.
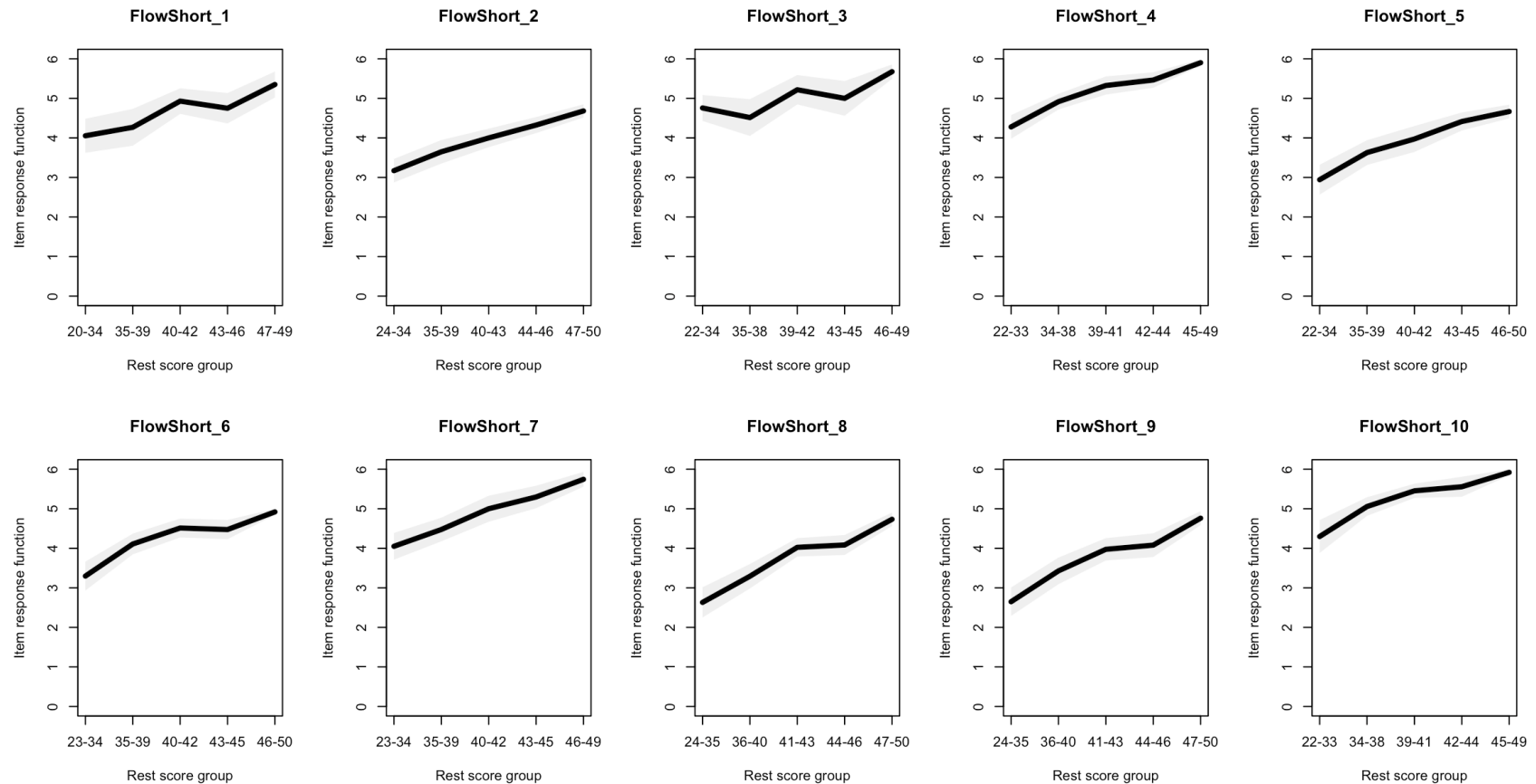

Figure 1: Monotonicity analysis of individual FSS items. The $x$-axis depicts the sum score of the whole scale. The $y$-axis depicts the item response function. Optimally all item response funsctions should be relatively diagonal, or at the very least without downward dips. Items 1 and 3 have a clear zig-zag -pattern, that is, a clear violation of monotonicity. 


\section{Table 2}

Item-level homogeneity analysis for Flow Short Scale.

\begin{tabular}{ccc}
\hline Item name & Homegeneity index & Standard error \\
\hline FlowShort_1 & 0.232 & .051 \\
FlowShort_2 & 0.404 & .038 \\
FlowShort_3 & 0.198 & .045 \\
FlowShort_4 & 0.472 & .033 \\
FlowShort_5 & 0.396 & .039 \\
FlowShort_6 & 0.412 & .039 \\
FlowShort_7 & 0.391 & .038 \\
FlowShort_8 & 0.436 & .037 \\
FlowShort_9 & 0.421 & .038 \\
FlowShort_10 & 0.419 & .038 \\
\hline
\end{tabular}

Note. Items with homogeneity index value $<.30$ are highlighted.

Table 3

Item selection for different levels of homogeneity index thresholds.

\begin{tabular}{cccccccccccccccccc}
\hline \multicolumn{10}{c}{ Level of Homogeneity } \\
\hline Item & .05 & .10 & .15 & .20 & .25 & .30 & .35 & .40 & .45 & .50 & .55 & .60 & .65 & .70 & .75 & .80 \\
\hline FlowShort_1 & 1 & 1 & 1 & 1 & 1 & 0 & 0 & 0 & 0 & 0 & 0 & 0 & 0 & 0 & 0 & 0 \\
FlowShort_2 & 1 & 1 & 1 & 1 & 1 & 1 & 1 & 1 & 1 & 2 & 0 & 0 & 0 & 0 & 0 & 0 \\
FlowShort_3 & 1 & 1 & 1 & 0 & 0 & 0 & 0 & 0 & 0 & 0 & 0 & 0 & 0 & 0 & 0 & 0 \\
FlowShort_4 & 1 & 1 & 1 & 1 & 1 & 1 & 1 & 1 & 1 & 1 & 1 & 0 & 0 & 0 & 0 & 0 \\
FlowShort_5 & 1 & 1 & 1 & 1 & 1 & 1 & 1 & 1 & 1 & 0 & 0 & 0 & 0 & 0 & 0 & 0 \\
FlowShort_6 & 1 & 1 & 1 & 1 & 1 & 1 & 1 & 1 & 1 & 1 & 1 & 1 & 1 & 1 & 1 & 1 \\
FlowShort_7 & 1 & 1 & 1 & 1 & 1 & 1 & 1 & 1 & 0 & 0 & 0 & 0 & 0 & 0 & 0 & 0 \\
FlowShort_8 & 1 & 1 & 1 & 1 & 1 & 1 & 1 & 1 & 1 & 2 & 2 & 2 & 2 & 0 & 0 & 0 \\
FlowShort_9 & 1 & 1 & 1 & 1 & 1 & 1 & 1 & 1 & 1 & 2 & 2 & 2 & 2 & 0 & 0 & 0 \\
FlowShort_10 & 1 & 1 & 1 & 1 & 1 & 1 & 1 & 1 & 1 & 1 & 1 & 1 & 1 & 1 & 1 & 1 \\
\hline
\end{tabular}

Note. Region of acceptable scalability, that retains a theoretically sensible scale structure, highlighted.

Next, we ran Parallel- and Very Simple Structure analyses [Revelle and Rocklin, 1979, Dima, 2018], both of which suggested that the 10 FSS items contain two factors. In the VSS analysis, a two-factor solution has maximum complexity with a fit index of .86. Increasing the number of factors does not result in lower (i.e. better) Bayes Information Criterion values (the minimum of -73.05 is reached with a two factor-solution; BIC-values in all other solutions were above -73). See Figure 2.

The analyses presented so far support dropping items 1 and 3, since they a) do not have the required level of homogeneity, and b) violate the monotonicity assumption. In other words, items 1 and 3 do not pass the Mokken scale analysis. Furthermore, items 1, 3, 6 and 10 are conceptually part of a separate subscale in the FSS. Both Parallel Analysis and VSS analysis suggest that there are two factors in the scale. We therefore repeated the Mokken scale analyses by leaving out items 1 and 3. These new analyses still suggested that there are two factors in the scale, and that items 6 and 10 still had a minor tendency to violate the monotonicity assumption. Based on simply the eigenvalue criterion, Parallel Analysis suggested there might be two factors, while the VSS analysis suggested that there were either two or three factors.

Based on the results of the Mokken scale analysis, we ran a Confirmatory Factor Analysis (CFA) by allowing items 6 and 10 to load on a separate factor from the rest of the items (see Figure 3 below). The resulting model had a relatively good fit with the data $\left(\chi^{2}(19)=51.93, \mathrm{CFI}=.94, \mathrm{TLI}=.91, \mathrm{RMSEA}=.093,90 \% \mathrm{CI}[.06, .12]\right.$, SRMR $=.055)$. However, as an exploratory analysis, we added a single error correlation between the items 8 and 9 , which had the highest modification index value (34.7). This substantially improved the scale: $\left(\chi^{2}(18)=31.07, \mathrm{CFI}=.97\right.$, $\mathrm{TLI}=.96, \mathrm{RMSEA}=.06,90 \% \mathrm{CI}[.027, .090], \mathrm{SRMR}=.041)$. We also fitted a single factor solution for the 8-item version of the scale, but this model had an unacceptable fit with the data $\left(\chi^{2}(18)=121.49, \mathrm{CFI}=.80, \mathrm{TLI}=.72\right.$, $\mathrm{RMSEA}=.16,90 \% \mathrm{CI}[.13, .18], \mathrm{SRMR}=.078)$; only by adding several error covariance terms could this version of 

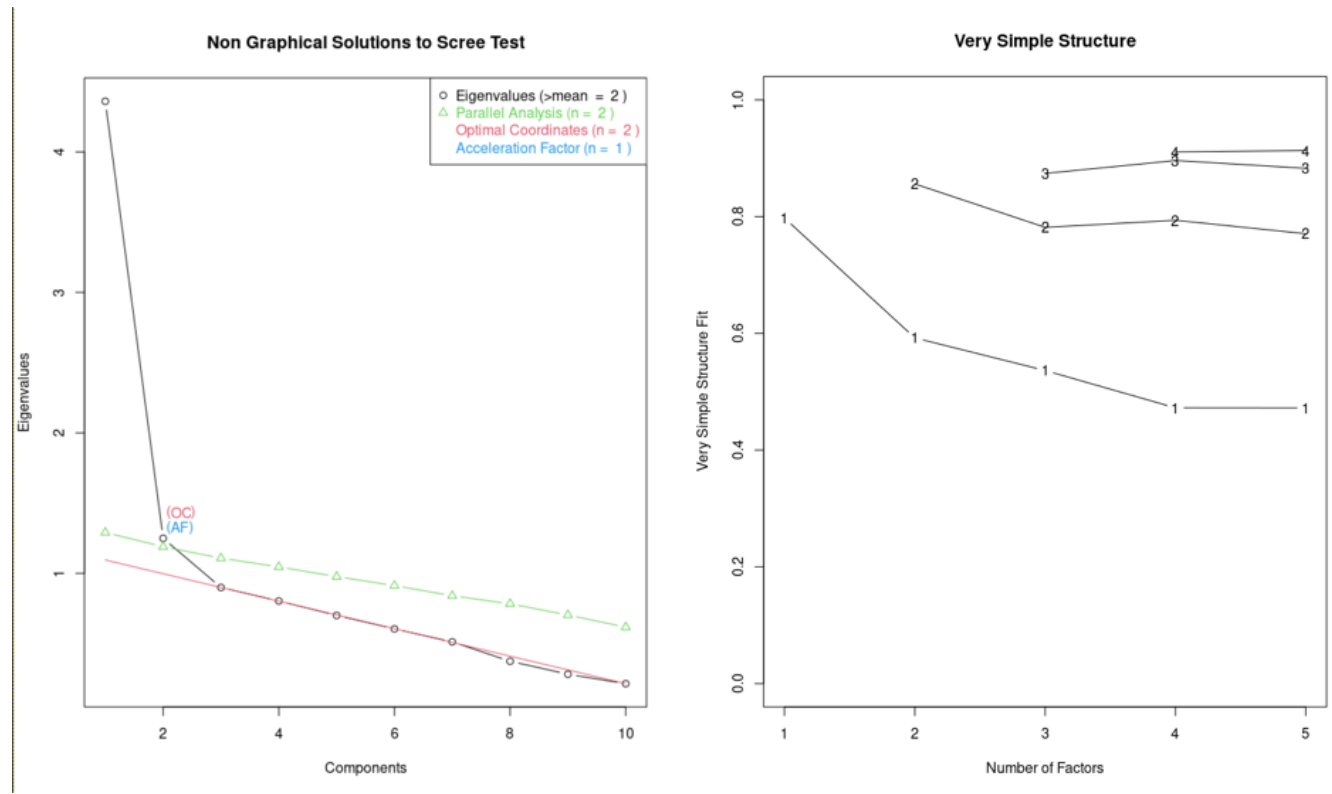

Figure 2: Left: Results of Parallel Analysis suggest that there are two factors contained in the 10 items that make the Flow Scale Short instrument. The green triangles represent random eigenvalues generated by the Parallel Analysis. The first two actually observed eigenvalues (black circles) were higher than the randomly generated eigenvalues (eigenvalue criterion). Right: Very Simple Structure analysis suggest that the two-factor solution is optimal. Increasing factors beyond 2 results in increase in $\mathrm{BIC}$-values.

the scale be brought to acceptable levels of usability. ${ }^{1}$ The principle of parsimony thus favors the 8-item, two-factor version presented in Figure 3, below. While it is generally recommended that three items should minimally be used to estimate latent factors, it is possible also by using only two items [Byrne, 2013, Shanmugam, 2020]. ${ }^{2}$

We also ran a sensitivity analysis on 6-, 8- and 10-item versions of the FSS. The 6-item version (i.e. the Fluency subscale) excluded items 1, 3, 6 and 10, while the 8-item version excluded items 1 and 3. Sensitivity analysis in this context is a correlation matrix where all three versions of the FSS are correlated with other conceptually related scales. The assessment is done qualitatively to estimate to what extent do correlations between the estimator variables fluctuate between the different scale candidates. As can be seen in Figure 4, all the correlations between the 6-, 8-, and 10-item versions of FSS are fairly similar.

To measure internal reliability, we calculated the Cronbach's alpha- and Tarkkonen's rho values for the 6-, 8and 10 -item version of the scale; these values were $0.83,0.84,0.86$ (Cronbach's alphas), and 0.71, 0.75, and 0.76 (Tarkkonen's rhos), respectively. These reliability measures indicate that the 8-item FSS version should be preferred. Cronbach's alpha values are sensitive to the number of items in the scale, but Tarkkonen's rho corrects against this sensitivity. All scale versions show good reliability in terms of Cronbach's alphas. However, in terms of Tarkkonen's rho, the 6-item version is barely above the cutoff point of .71 (where signal to noise ratio $>1$ ). The 8-item version is clearly above the cutoff point and not significantly different from the 10-item version (indicating that items 1 and 3 bring noise to the construct).

In terms of external validity, the translated scale has already been used as a dependent variable in two studies [Cowley et al., 2019, Palomäki et al., 2021], which yielded sensible and strong findings (thus demonstrating the scale has good predictive properties in terms of both actual and self-reported behaviors). Moreover, the sensitivity analysis performed in this paper further links the translated FSS with known scales with good demonstrated external validity.

\footnotetext{
${ }^{1}$ We ran an additional CFA by adding a super-ordinate factor into the model. We did by firstly by merely adding an extra factor, and secondly by running a Schmid-Leiman ( $\mathrm{g}$-factor) analysis. Both of these models failed to converge properly and did not yield proper standard errors of the estimates. See our analysis script for further details.

${ }^{2}$ We also ran a parallel analysis on the 8 -item version of the scale. The results (excluding the Keizer criterion) indicated that there was only one factor. We also note that the predictive validity of the translated FSS did not change substantially depending on which version of the scale was used; though the 8-item scale had the most robust structure.
} 


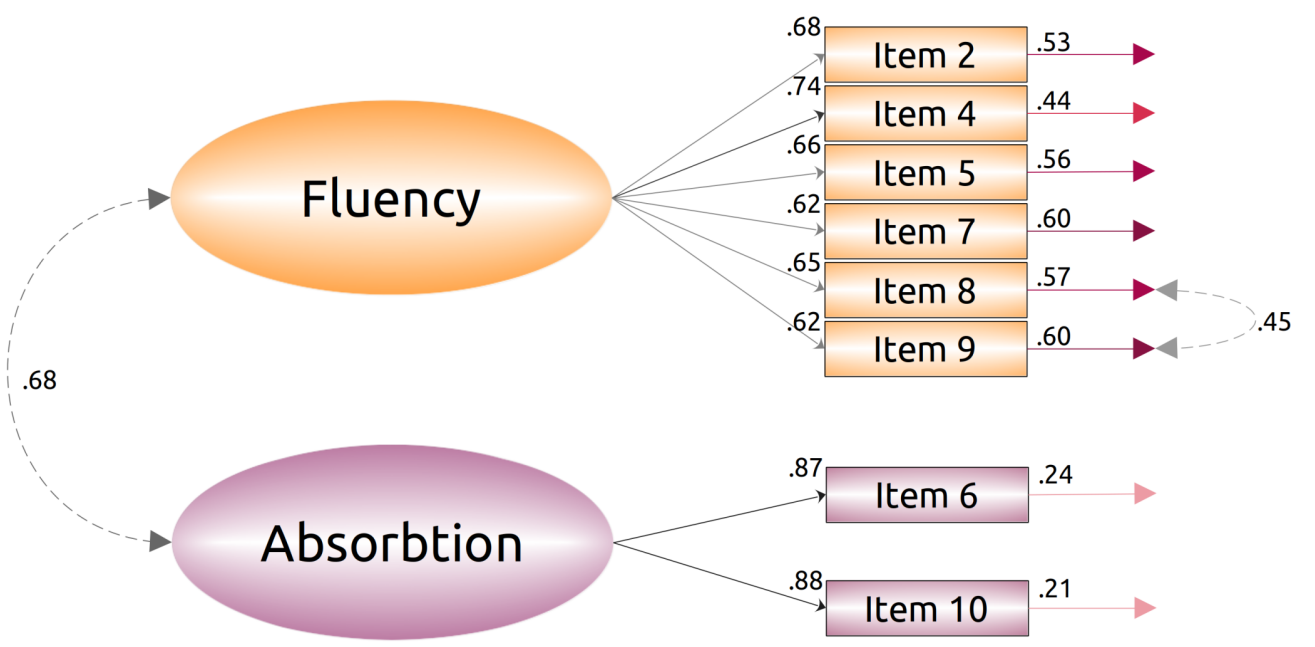

Figure 3: Final Confirmatory Factor Analysis for the 8-item Finnish FSS. This model has a good fit with the data: $\chi^{2}(18)$ $=31.07, \mathrm{CFI}=.97, \mathrm{TLI}=.96, \mathrm{RMSEA}=.06,90 \% \mathrm{Cl}[.027, .090], \mathrm{SRMR}=.041$.

Finally, to evaluate how sensitive the FSS is to the difference between "boring" and "Flow-like" experiences, we ran a paired samples t-test comparing the two instruction conditions (see section 2.3.4 "Task instructions"). It is evident that the scale still functions as intended irrespective of how many items are included (6-item version: $\mathrm{t}(200)=17.8, \mathrm{p}$ $<.001 ; 8$-item version: $\mathrm{t}(200)=22.6, \mathrm{p}<.001 ; 10$-item version: $\mathrm{t}(200)=28.5, \mathrm{p}<.001)$; see Figure 5 .

\section{Discussion}

Our well-powered, comprehensively-analysed, scale-validation study provides results that support the use of our Finnish translation of FSS with an 8-item, 2-factor version, which complements the state of the art of Flow measurement.

We also examined the 6-item version corresponding to only the 'Fluency' sub-scale, but ultimately, although this version does quite well in technical analysis, the choice should also be guided by a valid element of conservatism. Scales should develop with data incrementally, that is, not vary too wildly across studies (on vagaries of individual datasets). Another way to state it is that a scale is a model designed to predict a latent variable, and predictive models should always be hedged against overfitting to training data, to enhance generality and thus predictive power.

Although the FSS represents the Flow experience as a unidimensional measure with 2 contributing conceptual factors, fluency and absorption, our analyses do not clearly support this conclusion. Do these two factors capture enough of the content of Flow, and are there other options? One must answer such questions by looking at the statistics of the data collected with the instrument, i.e. do they support the 2 factor solution? For our translation, the analyses suggest yes, though not with the items the original authors suggested. And one must also examine the semantics of the items, i.e. do they capture core aspects of Flow as revealed by other self-report methods? Again our analyses suggest yes. And yet, the analyses do not constrain us to our chosen solution, and so (just as there was originally), there remains no empirical reason to separate fluency and absorption. They reflect a particular choice made by the original researchers developing the scale.

In comparing the 8-item, two-factor solution with the original 10-item scale, it is particularly notable that item 1 ("I feel just the right amount of challenge") failed to load on either factor. This replicates a result from a study which examined the psychometric properties of a Greek version of the FSS Kyriazos et al. [2018]. Csikszentmihalyi Csikszentmihalyi [1975] did not conceptualize perceived challenge as a phenomenological element of flow experiences, but as a condition which fosters them. Thus, given that item 1 has neither conceptual nor empirical justification, we believe there is good reason to drop the item from all future versions of the FSS. 

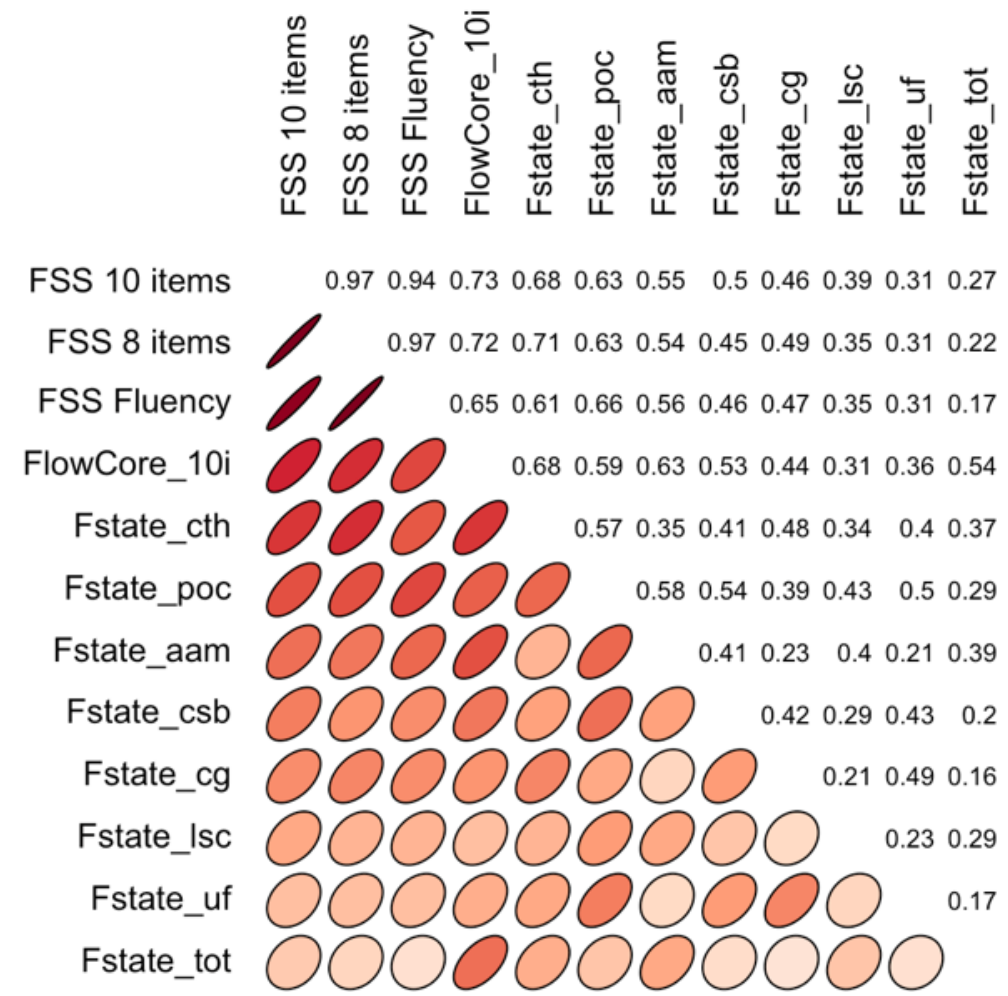

Figure 4: Sensitivity analysis (correlation matrix and visualization) for different versions of FSS. FSS = Flow Short Scale; FSS Fluency $=6$ item FSS comprising only Fluency subscale; Fstate $=$ Flow State Scale; $c$ th $=$ Concentration on task at hand; poc $=$ Paradox of control; aam = Action-awareness merging; $c s b=$ Challenge-skill balance; $c g=$ Clear goals; Isc $=$ Loss of self-consciousness; uf $=$ Unambiguous feedback; tot $=$ Transformation of time. The ellipses and their colours depict the strength of the correlation (thinner and darker ellipse $=$ stronger correlation).

\subsection{Limitations}

Despite the many positive attributes of the FSS, it is not a perfect scale. One notable limitation is that it does not measure one of the key components of the Flow experience - its autotelic (i.e. enjoyable; intrinsically motivating) nature. From the beginning, Csikszentmihalyi explicitly conceptualized Flow as a form of enjoyment Abuhamdeh [2021]. It was the enjoyable nature of Flow, and the positive implications this enjoyment had for motivation, he argued, that positioned it as a vehicle for skill development and personal growth (i.e., greater 'complexity') Csikszentmihalyi and Rathunde [1998]. Given the centrality of enjoyment in Csikszentmihalyi's conceptualization of Flow, it seems important for this aspect of the experience to be represented in the FSS.

A second limitation of the FSS relates to its scale of measurement. Whereas Flow, as an 'optimal' state of consciousness, represents a discrete state, the FSS, like all Flow scales, operationalizes Flow as a continuous state, ranging from 'low flow' to 'high flow'. Because level of intensity is built into the Flow construct, this results in conceptual imprecision. Kawabata and Evans Kawabata and Evans [2016] proposed one way to deal with this inconsistency: by designating a 'Flow cutoff' when using Flow scales.

Item 3 describes the passing of time. This is problematic if the scale is to be used generally, in a wide variety of contexts with huge differences in the duration and time-constraints of the task. For instance, consider the study of athletic performance - how time is experienced is clearly different in a $100 \mathrm{~m}$ dash that lasts $10 \mathrm{~s}$ vs. an ultramarathon lasting up to several days - yet, arguably, Flow can be achieved in both. 

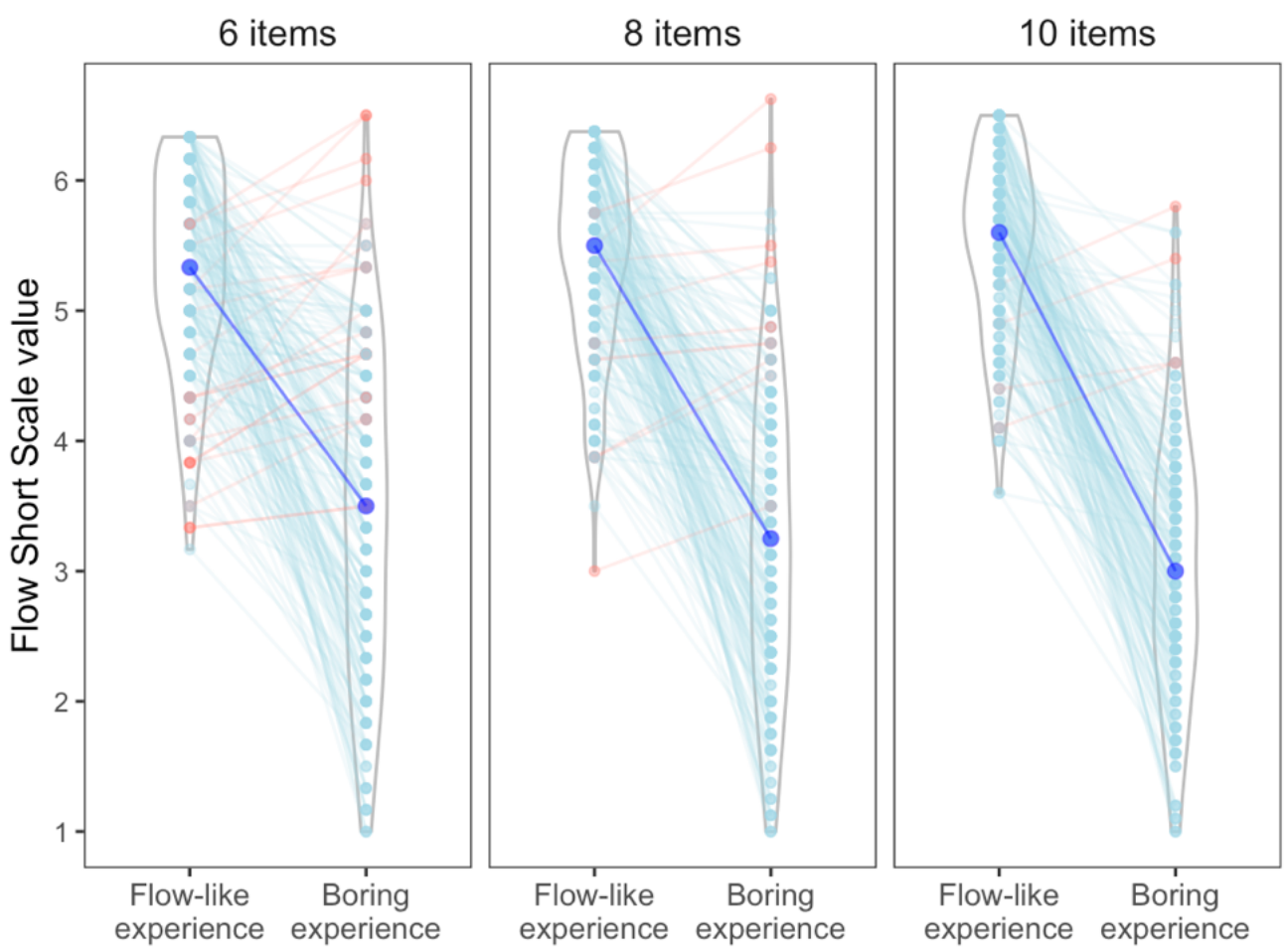

Figure 5: Comparison of Flow Short Scale (FSS) values between a Flow-like experience and a boring experience, separately for 6-item-, 8-item-, and 10-item versions of FSS. Large blue dots represent median values, and the smaller dots represent observations from individuals. Red slopes indicate individuals who reported experiencing more Flow during a "boring" experience.

\subsection{Future work}

Our work, including the literature search described in the Introduction, highlights a major lacuna in the toolbox of optimal experience researchers globally. Specifically, although reports on research are typically published in English, self-report data should ideally be gathered in participants' native language. This is particularly important when working with constructs such as Flow that derive from the semantic analysis of self-reports (originally, interviews conducted by Csikszentmihalyi and coworkers in the 1960s and 70s). As we are limited to a single study, future work should also test the properties of the Finnish FSS in subsequent independent samples.

There are substantial resources and guidelines invested in making such validated translations available for, e.g. intelligence quotient instruments Tanzer and Sim [1999]. Although domain-specific re-validated translations by individual research groups are no doubt valuable, there is a clear need for a standardised general-purpose instrument available in multiple languages.

\subsection{Conclusion}

We have presented a psychometric validation of the Flow Short Scale in a Finnish language translation. Considering the current fleet of validated Flow scales, we believe the FSS represents one of the better options out there. The FSS is short, consisting of only 10 items, and such brevity is desirable given that Flow is often measured in repeated-measures designs. Compared to the Flow State Scale (the most commonly used Flow scale), the FSS conflates the experience of Flow with the conditions of Flow to a lesser extent Abuhamdeh [2020]. Finally, the FSS is commonly used in Flow research, which means that its results can be meaningfully compared across a number of studies.

Given the challenges described above, the need for a standardised general-purpose instrument available in multiple languages seems to be one that calls for a consensus-driven international consortium project, which would move us closer to harmonising the field of Flow research. 


\section{References}

Jeanne Nakamura and Mihaly Csikszentmihalyi. The concept of flow. In C. R. Snyder and Shane J. Lopez, editors, Handbook of positive psychology, pages 89-105. Oxford University Press, New York (NY), 2002.

Sami Abuhamdeh. Investigating the "Flow" Experience: Key Conceptual and Operational Issues. Frontiers in Psychology, 11, 2020. ISSN 1664-1078. doi: 10.3389/fpsyg.2020.00158.

Susan A Jackson and Herbert W Marsh. Development and validation of a scale to measure optimal experience: The flow state scale. Journal of sport and exercise psychology, 18(1):17-35, 1996.

Stefan Engeser and Falko Rheinberg. Flow, performance and moderators of challenge-skill balance. Motivation and Emotion, 32(3):158-172, 2008.

B.A.K. Thissen, W. Menninghaus, and W. Schlotz. Measuring optimal reading experiences: The reading flow short scale. Frontiers in Psychology, 9(DEC), 2018. ISSN 16641078. doi: 10.3389/fpsyg.2018.02542.

R. Mahnke, T. Wagner, and A. Benlian. Flow experience on the web: Measurement validation and mixed method survey of flow activities. Association for Information Systems, 2012. ISBN 9788488971548.

L.-J. Huang, F.-C. Hu, C. Wu, Y.-H. Yang, S.-C. Lee, Y.-C. Fang, H.-C. Huang, K.-Y. Lai, and C.-Y. Yu. Traditional-chinese dispositional flow scale-2 and flow state scale-2 in taiwanese subjects with schizophrenia or schizoaffective disorder. Psychiatry Research, 274:287-293, 2019. ISSN 01651781. doi: 10.1016/j.psychres.2018.12.093.

E. Çağlar, I. Sari, F.H. Aşçi, R.C. Eklund, and S.A. Jackson. Short versions of turkish flow scales for athletes: Reliability and validity study. Studia Psychologica, 62(3):179-197, 2020. ISSN 00393320. doi: 10.31577/SP.2020.03.799.

J.A.E. Hernandez and R.D.C. Voser. Validity evidence for the flow state scale-2 with university athletes. Paideia, 29, 2019. ISSN 0103863X. doi: $10.1590 / 1982-4327 \mathrm{e} 2909$.

T. García Calvo, R. Jiménez Castuera, F.J. Santos-Rosa Ruano, R. Reina Vaíllo, and E. Cervelló Gimeno. Psychometric properties of the spanish version of the flow state scale. Spanish Journal of Psychology, 11(2):660-669, 2008. doi: 10.1017/s1138741600004662.

J. Fournier, P. Gaudreau, P. Demontrond-Behr, J. Visioli, J. Forest, and S. Jackson. French translation of the Flow State Scale-2: Factor structure, cross-cultural invariance, and associations with goal attainment. Psychology of Sport and Exercise, 8(6):897-916, 2007. doi: 10.1016/j.psychsport.2006.07.007.

G. Doganis, P. Iosifidou, and S. Vlachopoulos. Factor structure and internal consistency of the greek version of the flow state scale. Perceptual and Motor Skills, 91(4):1231-1240, 2000. doi: 10.2466/pms.2000.91.3f.1231.

L. Moral-Bofill, M. Andrés Lópezdelallave, C. Pérez-Llantada, and F.P. Holgado-Tello. Adaptation to spanish and psychometric study of the flow state scale-2 in the field of musical performers. PLoS ONE, 15(4), 2020. ISSN 19326203. doi: 10.1371/journal.pone.0231054.

K. Yoshida, K. Asakawa, T. Yamauchi, S. Sakuraba, D. Sawamura, Y. Murakami, and S. Sakai. The flow state scale for occupational tasks: Development, reliability, and validity. Hong Kong Journal of Occupational Therapy, 23(2):54-61, 2013. ISSN 15691861. doi: 10.1016/j.hkjot. 2013.09.002.

M. Kawabata, C.J. Mallett, and S.A. Jackson. The flow state scale-2 and dispositional flow scale-2: Examination of factorial validity and reliability for japanese adults. Psychology of Sport and Exercise, 9(4):465-485, 2008. ISSN 14690292. doi: 10.1016/j.psychsport.2007.05.005.

E.F.M. Riva, G. Riva, C. Talò, M. Boffi, N. Rainisio, L. Pola, B. Diana, D. Villani, L. Argenton, and P. Inghilleri. Measuring dispositional flow: Validity and reliability of the dispositional flow state scale 2, italian version. PLoS ONE, 12(9), 2017. ISSN 19326203. doi: 10.1371/journal. pone.0182201.

Theodoros A. Kyriazos, Anastassios Stalikas, Konstantina Prassa, Michael Galanakis, Katerina Flora, and Varvara Chatzilia. The Flow Short Scale (FSS) Dimensionality and What MIMIC Shows on Heterogeneity and Invariance. Psychology, 9(6):1357-1382, June 2018. doi: 10.4236/ psych.2018.96083. URL http://www.scirp.org/Journal/Paperabs.aspx?paperid=85702. Number: 6 Publisher: Scientific Research Publishing.

Falko Rheinberg, Regina Vollmeyer, and Stefan Engeser. Die erfassung des flow-erlebens. Diagnostik von Motivation und Selbstkonzept / hrsg. von Joachim Stiensmeier-Pelster und Falko Rheinberg. - Göttingen [u.a.] : Hogrefe, 2003. - (Tests und Trends ; N.F., 2). - ISBN 3-8017-1674-0. - S. 261 - 279, 092003.

Cyril Brom, Filip Děchtěrenko, Nikola Frollová, Tereza Stárková, Edita Bromová, and Sidney K. D’Mello. Enjoyment or involvement? Affectivemotivational mediation during learning from a complex computerized simulation. Computers \& Education, 114:236-254, 2017. ISSN 1873782X(Electronic),0360-1315(Print). doi: 10.1016/j.compedu.2017.07.001. Place: Netherlands Publisher: Elsevier Science.

Kaspar Schattke, Veronika Brandstätter, Geneviève Taylor, and Hugo M. Kehr. Flow on the rocks: Motive-incentive congruence enhances flow in rock climbing. International Journal of Sport Psychology, 45(6):603-620, 2014. ISSN 0047-0767(Print). Place: Italy Publisher: Edizioni Luigi Pozzi.

David J Harris, Samuel J Vine, and Mark R Wilson. Is flow really effortless? The complex role of effortful attention. Sport, Exercise, and Performance Psychology, 6(1):103-114, 2017. ISSN 2157-3913(Electronic),2157-3905(Print). doi: 10.1037/spy0000083.

Johanna M. Hermann and Regina Vollmeyer. "Girls should cook, rather than kick!"-Female soccer players under stereotype threat. Psychology of Sport and Exercise, 26:94-101, 2016. ISSN 1878-5476(Electronic),1469-0292(Print). doi: 10.1016/j.psychsport.2016.06.010. Place: Netherlands Publisher: Elsevier Science.

Benjamin Ultan Cowley, Jussi Palomäki, Tuisku Tammi, Roosa Frantsi, Ville-Pekka Inkilä, Noora Lehtonen, Pasi Pölönen, Juha Vepsäläinen, and Otto Lappi. Flow experiences during visuomotor skill acquisition reflect deviation from a power-law learning curve, but not overall level of skill. Frontiers in psychology, 10:1126, 2019.

J. P. Palomäki, T. Tammi, N. Lehtonen, N. Seittenranta, M. Laakasuo, S. Abuhamdeh, O. Lappi, and B. U. Cowley. The link between flow and performance is moderated by task experience. Computers in Human Behaviour, in press, 2021.

Andrew J Martin and Susan A Jackson. Brief approaches to assessing task absorption and enhanced subjective experience: Examining 'short'and 'core'flow in diverse performance domains. Motivation and Emotion, 32(3):141-157, 2008.

Klaas Sijtsma and L Andries van der Ark. A tutorial on how to do a mokken scale analysis on your test and questionnaire data. British Journal of Mathematical and Statistical Psychology, 70(1):137-158, 2017. 
William Revelle and Thomas Rocklin. Very simple structure: An alternative procedure for estimating the optimal number of interpretable factors. Multivariate Behavioral Research, 14(4):403-414, 1979.

Alexandra L Dima. Scale validation in applied health research: tutorial for a 6-step r-based psychometrics protocol. Health Psychology and Behavioral Medicine, 6(1):136-161, 2018.

Wim J van der Linden. Handbook of Item Response Theory: Volume 1: Models. CRC Press, 2016.

Barbara M Byrne. Structural equation modeling with Mplus: Basic concepts, applications, and programming. routledge, 2013.

Ramalingam Shanmugam. Handbook of item response theory: Volume one, models, 2020.

Mihalyi Csikszentmihalyi. Play and Intrinsic Rewards. Journal of Humanistic Psychology, 15(3):41-63, 1975.

Sami Abuhamdeh. On the Relationship Between Flow and Enjoyment. In Corinna Peifer and Stefan Engeser, editors, Advances in Flow Research, pages 155-169. Springer International Publishing, Cham, 2021. ISBN 978-3-030-53468-4. doi: 10.1007/978-3-030-53468-4_6. URL https: //doi.org/10.1007/978-3-030-53468-4_6.

Mihaly Csikszentmihalyi and Kevin Rathunde. The development of the person: An experiential perspective on the ontogenesis of psychological complexity. In Handbook of child psychology: Theoretical models of human development, Volume 1, 5th ed, pages 635-684. John Wiley \& Sons Inc, Hoboken, NJ, US, 1998. ISBN 978-0-471-05527-3.

Masato Kawabata and Rachel Evans. How to Classify Who Experienced Flow from Who Did Not Based on the Flow State Scale-2 Scores: A Pilot Study of Latent Class Factor Analysis. The Sport Psychologist, 30(3):267-275, September 2016. ISSN 0888-4781, 1543-2793. doi: 10.1123/tsp.2014-0053. URL https://journals.humankinetics.com/view/journals/tsp/30/3/article-p267.xml. Publisher: Human Kinetics, Inc. Section: The Sport Psychologist.

Norbert K. Tanzer and Catherine Q.E. Sim. Adapting Instruments for Use in Multiple Languages and Cultures: A Review of the ITC Guidelines for Test Adaptations. European Journal of Psychological Assessment, 15(3):258-269, September 1999. ISSN 1015-5759. doi: 10.1027//1015-5759. 15.3.258. Publisher: Hogrefe Publishing. 